\title{
JUDGMENT OF THE MORALITY OF AN INDIVIDUAL RESPONSIBLE FOR A FATAL WORKPLACE ACCIDENT INVOLVING SUBORDINATES
}

\author{
${ }^{1}$ University of Silesia, Katowice, Poland \\ Faculty of Pedagogy and Psychology, Institute of Psychology \\ ${ }^{2}$ Silesian University of Technology, Gliwice, Poland \\ University College of Social Sciences and Philologies
}

\begin{abstract}
Background: The aim of the study was to verify the hypothesis that additional information about the perpetrator responsible for the death of subordinates at the workplace may influence the assessment of morality. The article contains the results of an empirical study conducted among young adult working Silesians $(\mathrm{N}=262)$, who were asked to evaluate the morality of the person responsible for the decision, in line with which miners had started working on 6th October 2014. On that day miners died following an explosion in the "Mysłowice-Wesoła" methane mine in the Polish Silesia region. Material and Methods: The study explored the stories' method (from the moral psychology domain) as well as a short questionnaire. The respondents received information about the behavior of the perpetrator as well as emotions (socially desirable and undesirable) and (socially desirable and undesirable) views in the form of brief descriptions (stories). They were asked to evaluate the perpetrator's morality. Results: The socially desirable views of the evaluated perpetrator (lack of acceptance for the situation) and the socially desirable emotions (guilt) significantly increased the level of morality according to participants. A single piece of information about the socially desirable emotions didn't significantly increase the perceived level of perpetrator's morality; neither did a single piece of information about socially desirable views. Conclusions: Results indicate the important role of additional information about emotions and views of the perpetrator in the process of assessing morality. It is worthwhile to implement the practical implications of this study in similar crisis situations at the workplace. Med Pr 2018;69(3):261-267
\end{abstract}

Key words: moral incoherence, moral coherence, moral judgments, moral psychology, morality, mining

Corresponding authors: Mariola Paruzel-Czachura, University of Silesia, Faculty of Pedagogy and Psychology, Institute of Psychology, Grażyńskiego 53, 40-126 Katowice, Poland, e-mail: mariola.paruzel-czachura@us.edu.pl; Małgorzata Dobrowolska, Silesian University of Technology, University College of Social Sciences and Philologies, Hutnicza 9-9A, 44-100 Gliwice, Poland, e-mail: malgorzata.dobrowolska@polsl.pl

Received: June 23, 2017, accepted: December 21, 2017

\section{INTRODUCTION}

On 6 October 2014, methane exploded in the "Mysłowice-Wesoła" mine, leaving 37 miners dead or injured. After the explosion, the media reported that the person responsible for the relevant decision had consciously ordered the miners to commence work despite the elevated risk, focusing on the economic aspects of the mine's operation.

On the grounds of the concept of moral integrity and the lack thereof [1-3], which emphasizes not only the role of behavior but also that of the views expressed and the emotions felt by the perpetrator when it comes to judging morality, a study was conducted among young working adults living in Silesia $(\mathrm{N}=262)$, who were asked to judge the morality of the person respon- sible for the decision ordering the miners to go underground to work, leading to deaths and injuries. This paper contains the findings from the said study, with an indication of the latter's limitations and of the practical implications that may find application in similar critical situations at work.

A number of analyses have been conducted in the field of moral psychology concerning factors important in the process of making decisions concerning other people's morality. For example, the significant role of the emotions felt and of the views expressed by the other person was demonstrated when it came to judging morality [3]. In spite of that, the literature lacks research concerning the aspects discussed here, in the context of disasters, in a particular place of work in Silesia, namely an underground mine with methane

Funding: this work was supported by National Science Center, Miniatura 1 (project No. 2017/01/X/HS6/0133 entitled "Moral consistency: relation between moral behaviors, views and emotions - pilot study", head of research project: Mariola Paruzel-Czachura, Ph.D.). 
explosion, flooding and tremor hazards. Although we judge the morality of people around us on a daily basis and we are capable of expressing opinions about it within 200-250 ms [4], fatal accidents at work represent very particular situations as far as moral decisions are concerned.

Firstly, contributing to someone else's death is considered a very serious offense in most cultures, while manslaughter is described from the angle of the universal hierarchy of values in the world [5]. Secondly, the critical situation in the "Mysłowice-Wesoła" mine described here concerns a mass death. The consequences of the action are therefore more intense than in the case of a single fatal incident at work. The intensity of the effects is significant for our moral judgments [5]. Thirdly, the person responsible for the miners going underground was aware of the elevated explosion hazard, and analyses have shown that the controllability of factors contributes to a more severe judgment of the other person's morality [6]. Fourthly, approximately a half of all the study subjects declared that miners were part of their nearest social circle. The situation being assessed may have therefore affected their nearest and dearest directly.

The main research question is whether information about the perpetrator's emotions and views (socially desirable and undesirable ones) is important for the judgment of morality from the onlooker's point of view. According to the person-centered theory, we make moral judgments taking into account not only the action but the whole person [7]. The information about the perpetrator's views and emotions was therefore expected to influence the judgment of morality, and the study subjects were expected to judge more positively a perpetrator feeling socially desirable emotions and expressing social desirable views because we prefer individuals who have the highest possible moral integrity $[2,8-10]$. So far, most research in the psychology of moral judgments has focused on analyzing the behavior itself or the behavior and views of other people. Over the recent years, however, the increasingly important role of including emotional aspects in research in the field of moral psychology has been emphasized [11-14], and consequently this study also takes into account information about the perpetrator's emotions, apart from their behavior and views.

Moral integrity may concern 3 aspects of morality: behavior, views, and emotions [3]. This concept is related to the assumption that morality is not only what we do but also what we think and what we feel. We have moral integrity for instance when we tell the truth, we believe that one should tell the truth, and we are happy about it. This is positive integrity (because this kind of morality is socially desirable). However, when we tell lies, we believe that lying is acceptable and we are happy about it, we also have integrity, but it is negative because most societies believe lying to be undesirable in their value systems. This is the vertical integrity type described by Żylicz [15].

Lack of moral integrity is commonly referred to as "moral schizophrenia" [3]. It appears when there is inconsistency between 2 or 3 aspects of morality. For example, we believe telling lies to be unacceptable, we tell lies and we do not feel guilt. Other examples of the lack of moral integrity described in the psychological literature constitute the concept of bounded ethicality $[16,17]$, moral hypocrisy $[1,18]$, and ethical dissonance [2].

In the study discussed in this paper, the respondents were shown the 4 possible types of integrity and lack thereof, described further below. The expectation was that the study subjects would prefer socially desirable emotions and views, i.e., that the perpetrators displaying them would be judged as the most moral. Other research has shown that we perceive moral hypocrisy negatively [19], and that we prefer individuals who have positive moral integrity [3]. It was also assumed that socially desirable emotions would be preferred over socially undesirable ones. A similar assumption was made in the case of views, which is rather obvious. A number of studies emphasize the role of intention, feeling of guilt and apologies on the perpetrator's part in the process of judging them [20-22]. It is therefore slightly more interesting to examine the preferences concerning socially (un)desirable emotions or socially (un)desirable views. Socially desirable views were expected to be more important for the study subjects than socially desirable emotions. This would be related to the fact that views are more stable and controllable than emotions, so we expect them to be more "appropriate" as compared to emotions [6].

Summing up, the following hypotheses were put forward in the research:

Hypothesis 1: The study subjects will judge as more moral the individual expressing socially desirable views and feeling socially desirable emotions vs. the other options.

- Hypothesis 2: The study subjects will judge as more moral the individual expressing socially desirable views and feeling socially undesirable emotions 
vs. the individual feeling socially desirable emotions and expressing socially undesirable views.

Hypothesis 3: The study subjects will judge as the least moral the individual expressing socially undesirable views and feeling socially undesirable emotions vs. the other options.

\section{MATERIAL AND METHODS}

The individuals participating in the incident (including onlookers, the victims' neighbors, people living in nearby housing estates and towns, people working at nearby companies in the area of the Silesian Province) were asked to judge the morality of the perpetrator responsible for the miners going underground in the "Mysłowice-Wesoła" mine, who had contributed to the miners' death or injury. They were given 4 potential situations (stories) to judge, containing:

socially desirable views and emotions,

socially desirable views and socially undesirable emotions,

socially undesirable views and socially desirable emotions,

socially undesirable views and emotions.

The feeling of guilt was a socially desirable emotion, while the lack thereof was a socially undesirable one. Information about the perpetrator's conviction that the situation should not have happened (work should not have been continued if a more serious hazard was present as compared to the ordinary conditions) represented a socially desirable view, while information that the perpetrator believed that the situation could take place (that it was acceptable to continue work under conditions of elevated hazard) represented a socially undesirable view.

For example, one of the stories went as follows. "Imagine that an individual (a group) responsible for the miners going underground (the decision-makers) felt guilty as a result of the victims' tragedy and believed that the situation should not have taken place (work should not have continued under conditions of elevated hazard). Please indicate on a scale of 0 to 7 the degree to which you consider this individual a moral person."

The research procedure described in this paper was inspired by numerous studies by Wojciszke [23] and Haidt $[11,24]$ using a formula that involved presenting short stories to the study subject, asking them to judge the morality of the individuals the stories concerned. This is an example of a recognized approach in the psychology of moral judgments.
The respondents judged morality on a scale of 0 to 7 $(0$ - a very immoral individual, 7 - a very moral individual). Each subject assessed 4 possible situations. Other aspects that were controlled were age, gender, province of residence, status of the subject (e.g., student, worker, unemployed person), as well as the subjects' political views and whether they believed in and practiced a religion. The study subjects were also asked to state whether their closest family or friends included or had included miners.

Research in the area of values indicates that moral judgments depend on the degree of moral development, which is connected with age in an obvious manner $[6,15]$. Guided by our concern about the high internal and external accuracy of the research, we decided to invite young adults, i.e., people aged $20-30 / 35$ years old to participate in it, following Bee [25]. We have limited ourselves to that age range because people included in it constitute a relatively homogeneous group which starts to perceive the ethical relativism of many aspects [26].

Two hundred sixty-two young working adults living in Silesia took part in the anonymous research (age: mean $(\mathrm{M})=23.54$, standard deviation $(\mathrm{SD})=2.41$ ), of whom $67 \%$ were women $(\mathrm{N}=174)$. The study subjects were working for various employers (a total of several dozen various companies). Seventy-one percent of the respondents were students and workers $(\mathrm{N}=186)$ (the sample included students of state and private universities as well as post-secondary schools), and 30\% were only workers $(\mathrm{N}=76)$. The sample did not include miners but $53 \%(N=140)$ subjects declared that their closest family/friends included or had included miners. It is worth emphasizing, however, that the closest relatives and friends of miners who had died as a result of the explosion described in the survey were not asked to fill out the questionnaire.

Eighty-six percent of the subjects declared themselves as Catholic believers ( $\mathrm{N}=217), 12 \%$ as atheists $(\mathrm{N}=31), 1 \%$ as Buddhists $(\mathrm{N}=3)$, and $1 \%$ as agnostics $(\mathrm{N}=2)$. Nine persons did not respond to this question. All the atheists and agnostics in the sample had been raised in the Catholic faith. The subjects declared an average degree of practicing religious observances $(\mathrm{M}=3.66, \mathrm{SD}=2.37$, median $(\mathrm{Me})=4)$ on a scale of 0-7 (0 - "I do not practice at all," 7 - "I follow religious observances").

When asked about their political views concerning economic matters, the subjects gave average responses $(\mathrm{M}=3.65, \mathrm{SD}=1.7, \mathrm{Me}=4)$ on a scale of $0-7(0-$ "The State's involvement should be very limited," 7 - "The 
Table 1. Stories' method in the study of young adult $(\mathrm{N}=262)$ working Silesians, who were reading various stories about a perpetrator responsible for the death of subordinates at the workplace

\begin{tabular}{lcc}
\hline \multirow{2}{*}{ Story } & \multicolumn{2}{c}{$\begin{array}{c}\text { Perpetrator's morality } \\
\text { scale } \\
{[\mathrm{pts}]}\end{array}$} \\
\cline { 2 - 3 } & $\mathrm{M}$ & $\mathrm{SD}$ \\
\hline $\begin{array}{l}\text { A - story including emotions and views } \\
\text { socially desired }\end{array}$ & 4.24 & 1.74 \\
$\begin{array}{l}\text { B - story including socially desired views } \\
\text { and socially undesired emotions }\end{array}$ & 1.92 & 1.43 \\
$\begin{array}{l}\text { C - story including socially undesired views } \\
\text { and socially desired emotions }\end{array}$ & 1.93 & 1.41 \\
$\begin{array}{l}\text { D - story including emotions and views } \\
\text { socially undesired }\end{array}$ & 0.53 & 0.79 \\
\hline
\end{tabular}

$\mathrm{M}$ - mean, SD - standard deviation.

State's involvement should be very high"). Their responses were similar when they were asked about their political views concerning social and cultural matters $(\mathrm{M}=3.84, \mathrm{SD}=1.62, \mathrm{Me}=4)$ on a scale of $0-7(0-$ "Very conservative views," 7 - "Very liberal views").

\section{RESULTS}

A Friedman ANOVA test was carried out for the derivative measurements: Chi $^{2}$ ANOVA $(\mathrm{N}=262, \mathrm{df}=3)=$ $543.4224, \mathrm{p}<0.001$. The analysis confirmed the existence of significant differences between the stories. The Table 1 presents the mean and the standard deviation for all the stories, while the Figure 1 also contains data concerning the median value, and presents the results obtained in a visual form.

It was also checked whether additional variables controlled in the study (age, gender, political views, belief in and practicing of a religion, having miners among closest family members/friends) had a significant influence on the results obtained (Mann-Whitney U test, Kruskal-Wallis test). No significant results appeared in the analyses, which may be interpreted from the angle of universalism in the expression of moral judgments in this area. Similar tendencies have been obtained in other studies [3].

\section{DISCUSSION}

Hypotheses 1 and 3 were confirmed in accordance with the expectations $[3,6,19]$. It turns out that the information about the socially desirable views and emotions of the individual responsible for the miners' death leads to

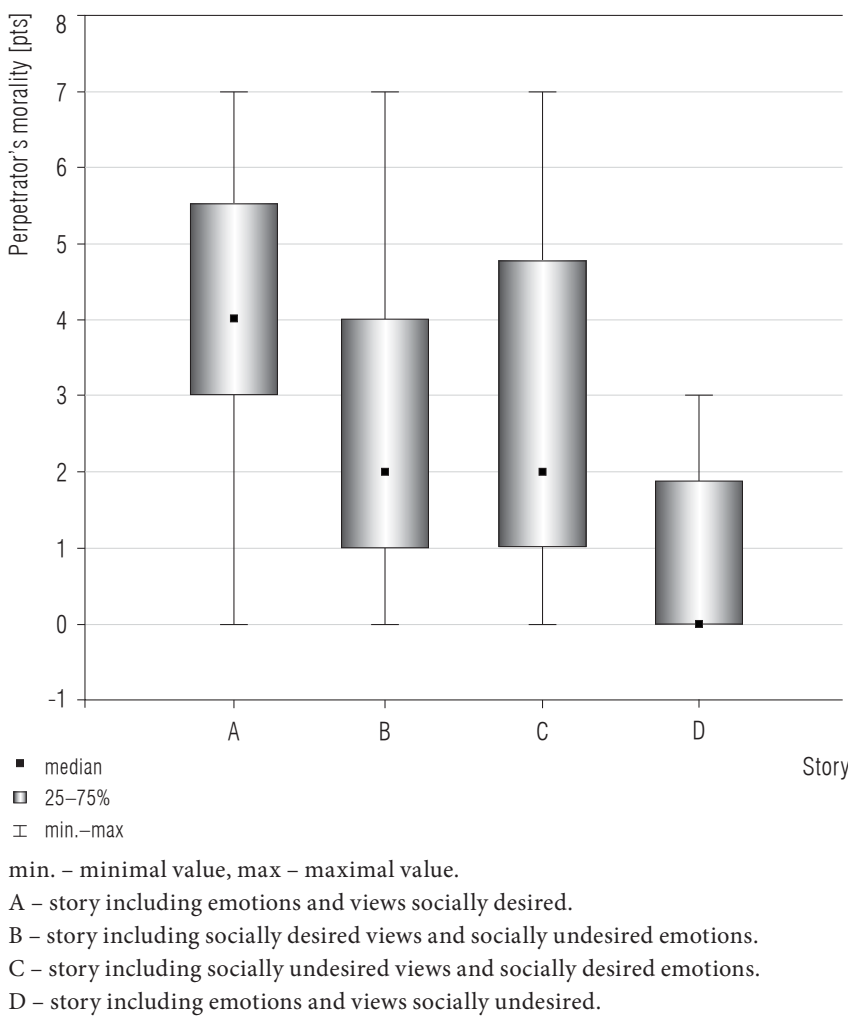

Fig. 1. Boxplot with stories' method in the study of young adult ( $\mathrm{N}=262$ ) working Silesians, who were reading various stories about a perpetrator responsible for the death of subordinates at the workplace

a significantly more positive judgment of that person's morality, while information about the socially undesirable views and emotions of the individual responsible for the miners' death leads to a significantly more negative judgment of that person's morality. Both the first and the last story differed significantly from all the others at the level of $\mathrm{p}<0.001$.

The hypothesis 2 was not confirmed, however, meaning that there was no difference for the study subjects between socially desirable views and emotions (as well as undesirable views and emotions). In other words: the sole information about socially desirable emotions will not contribute to a significantly more positive judgment of the morality of the given individual, nor will the sole information on desirable views. In turn, the sole information about socially undesirable emotions will not contribute to a significantly more negative judgment of the morality of the given individual, and nor will the sole information on undesirable views. Only the provision of information about socially desirable (or undesirable) views and emotions at the same time contributes to a significantly more positive (or negative) judgment of the morality of the perpetrator of the specific behavior. 


\section{CONCLUSIONS}

Although there may exist a widespread conviction about the significant role of behavior only when it comes to moral judgments, the latest research points to some additional aspects that influence our judgments concerning morality $[3,11-14]$. This paper describes 2 of them: the views expressed and the emotions felt by the individual responsible for the miners' fatal accident at work, as those having a significant influence on the perception of that person's morality. This data is consistent with the results confirming this tendency in the case of violation of other norms, such as "you shall not steal," "you shall not cheat on your partner," and "you shall not tell lies" [3].

Working young adults in Poland expressed a significantly more positive judgment of the morality of the individual feeling guilty after the miners' death or injury and who believed at the same time that the situation should not have taken place (that work should not have been continued under conditions of an elevated hazard). That individual's views and emotions were therefore desirable from the social point of view. It is worth emphasizing, however, that the same individual's morality was perceived significantly more positively by the study subjects only if the latter had information about socially desirable views and socially desirable emotions at the same time. Information provided only about socially desirable views or only about emotions did not have such a strong influence on the change of the judgment of the perpetrator's morality.

This tendency also worked in the opposite direction: socially undesirable views and emotions led to a significantly less positive judgment of the perpetrator's morality. It turns out, therefore, that the act itself is not the only significant piece of information taken into account by the study subjects when judging the morality of the miners' supervisor.

The above findings are important for several reasons. First of all, we make moral judgments every day, especially at work $[4,6]$. Secondly, it is natural for us to perceive people in moral (community) terms and in terms of agency (competencies/success), which Wojciszke has demonstrated many times in his research, also with his team [23]. Thirdly, our moral decisions (and consequently our system of values) influence many areas of our life, such as the election of political candidates $[27,28]$, the quality of business behavior or the choice of one's life partner [29]. What is more, the way in which we perceive other people's intentions influences even our altruistic behavior [30]. Fourthly, the analy- sis of the aspects significant for the judgment of the morality of key people at a company may have a significant influence on the latter's development, on the employees' sense of justice, on the feeling that human resources are being managed efficiently, on the image of the company in the local and global environment, etc.

The practical implications of the results obtained are related mainly to the perception of the managerial staff at the company in critical situations. It is important to inform the employees and other interested individuals about the socially desirable views and emotions of the persons responsible for the given situation because this will reduce the severity of the moral judgment and may alleviate the anxiety connected with the relevant crisis. Further studies are required in this field, however.

It is worth emphasizing that even though a half of the study subjects had miners among their nearest and dearest, no differences appeared between that group and the other study subjects. This means that working individuals perceive the moral aspects that were studied in a similar way, regardless of whether their closest family members or friends included miners who may have found themselves in a similar situation.

It is extremely important to carry out further analyses taking into account other critical situations in companies and situations when other ethical standards are violated. It is worth studying the nuances that may appear depending on the type of behavior. Various individuals could also be analyzed, judged from the point of view of their place within the organization (e.g., the president, the managerial staff, etc.), and the various types of businesses and their sizes could be taken into account.

It would also be interesting to expand the research to take into account additional variables pertaining to the study subject, such as personality traits, political views, the system of values, and an in-depth analysis of the individual's moral functioning. It would also be significant to expand the sample by adding other (especially older) age groups as well as to compare the extent to which judgments of the individuals involved in the situation differ from judgments of individuals from other provinces of Poland, without the social identity context of the Silesian Province.

The study's limitations include above all the particular sample comprising people living in the Silesian region, for whom mining disasters are particularly significant. The "Mysłowice-Wesoła" mine is considered the most dangerous mine in the region. It is not without importance that the said individuals were Catho- 
lic believers. On the other hand, similar research was carried out concerning the judgment of the morality of the perpetrators of the Boeing 777 crash on a Polish, Spanish, Czech, and Chinese sample, yielding similar results [3], which may prove the universality of expressing such moral judgments. It would therefore be worth conducting further research on samples from various countries, with control of cultural variables.

Furthermore, the methodology of the studies carried out may be problematic due to the fact that every study subject read all 4 stories. It seems more appropriate to use an experimental method involving every subject reading only 1 story. Paruzel-Czachura carried out research in 2016, controlling the method of obtaining the results in the questionnaire and in the experiment (with one study subject reading only a single story). It turned out that the same results were obtained in both methods with regard to the judgment concerning the most moral and least moral individuals. The said research concerned the situation of judging a cheating partner [3].

To conclude, it is worth pointing out that the study subjects obtained information not only about the behavior of the individual being judged but also about the emotions felt and the views expressed by the latter. This situation may seem artificial from the point of view of day-to-day life. It has to be pointed out, however, that even if we do not have access to other people's views and emotions, we still make certain assumptions to that effect, and these assumptions influence our moral judgments [6].

\section{ACKNOWLEDGEMENTS}

The authors would like to thank all the anonymous subjects for participating in the research, and they would also like to extend their sympathy to the miners, their families and friends affected by the tragedy resulting from the explosion of methane in the "Mysłowice-Wesoła" mine in Poland.

\section{REFERENCES}

1. Batson CD, Thompson GS, Whitney H, Strongman JA. Moral hypocrisy: Appearing moral to oneself without being so. J Pers Soc Psychol. 1991;77(3):525-37, https://doi. org/10.1037/0022-3514.77.3.525.

2. Barkan R, Ayal S, Ariely D. Ethical dissonance, justifications, and moral behavior. Curr Opin Psychol. 2015;6:157-61, https://doi.org/10.1016/j.copsyc.2015.08.001.

3. Paruzel-Czachura M. Moral judgments and moral integrity - Three empirical studies. In: Brand C, editor. Dual- process theories in moral psychology. Interdisciplinary approaches to theoretical, empirical and practical considerations. Wiesbaden: Springer VS; 2016. p. 159-84, https:// doi.org/10.1007/978-3-658-12053-5_8.

4. Van Berkum JJ, Holleman B, Nieuwland M, Otten M, Murre J. Right or wrong? The brain's fast response to morally objectionable statements. Psychol Sci. 2009;20(9): 1092-9, https://doi.org/10.1111/j.1467-9280.2009.02411.x.

5. Jones TM. Ethical decision making by individuals in organizations: An issue contingent model. Acad Manage Rev. 1991;16(2):366-95, https://doi.org/10.5465/AMR.1991. 4278958 .

6. Weiner B: Social motivation, justice, and the moral emotions: An attributional approach. Mahwah: Lawrence Erlbaum Associates; 2005.

7. Uhlmann EL, Pizarro DA, Diermeier D. A person-centered approach to moral judgment. Perspect Psychol Sci. 2015;10(1):72-81, https://doi.org/10.1177/174569161 4556679 .

8. Lu HJ, Chang L. The association between self-deception and moral self-concept as functions of self-consciousness. Pers Indiv Dif. 2011;51(7):845-9, https://doi.org/10.1016/ j.paid.2011.07.014.

9. Von Hippel W, Trivers R. The evolution and psychology of self-deception. Behav Brain Sci. 2011;34(1):1-16, https:// doi.org/10.1017/S0140525X10001354.

10. Bersoff DM. Why good people sometimes do bad things: Motivated reasoning and unethical behavior. Pers Soc Psychol. 1991;25(1):28-39, https://doi.org/10.1177/014616729 9025001003.

11. Haidt J. The righteous mind: Why good people are divided by politics and religion. New York: Vintage; 2013.

12. Koenigs M, Young L, Adolphs R, Tranel D, Cushman F, Hauser M, et al. Damage to the prefrontal cortex increases utilitarian moral judgments. Nature. 2007;446:908-11, https://doi.org/10.1038/nature05631.

13. Prinz J. The emotional construction of morals. Oxford: Oxford University Press; 2007.

14. Huebner B, Dwyer S, Hauser MD. The role of emotion in moral psychology. Trends Cogn Sci. 2009;13(1):1-6, http:// doi.org/10.1016/j.tics.2008.09.006.

15. Żylicz PO. [Moral psychology. Selected issues]. Academica: Warszawa; 2010. Polish.

16. Banaji MR, Bhaskar R. Implicit stereotypes and memory: The bounded rationality of social beliefs. In: Schacter DL, Scarry E, editors. Memory, brain, and belief. Harvard: Harvard University Press; 2000. p. 139-75.

17. Chugh D, Kern MCA. Dynamic and cyclical model of bounded ethicality. Res Organ Behav. 2016;36:1-16, https:// doi.org/10.1016/j.riob.2016.07.002. 
18. Stone J, Wiegand AW, Cooper J, Aronson E. When exemplification fails: Hypocrisy and the motive for self-integrity. J Pers Soc Psychol. 1997;72(1):54-65, https://doi. org/10.1037/0022-3514.72.1.54.

19. Barden J, Rucker DD, Petty RE, Rios K. Order of actions mitigates hypocrisy judgments for ingroup more than outgroup members. Group Processes Intergroup Relat. 2013; 17(5):590-601, https://doi.org/10.1177/1368430213510192.

20. Cushman F. Crime and punishment: Distinguishing the roles of causal and intentional analyses in moral judgment. Cognition. 2008;108(2):353-80, https://doi.org/10.1016/ j.cognition.2008.03.006.

21. Malle BF, Guglielmo S, Monroe AE. A theory of blame. Psychol Inq. 2014;25(2):147-86, https://doi.org/10.1080/ 1047840X.2014.877340.

22. Kim PH, Dirks KT, Cooper CD, Ferrin DL. When more blame is better than less: The implications of internal vs. external attributions for the repair of trust after a competence - vs. integrity - based trust violation. Organ Behav Hum Decis Process. 2006;99(1):49-65, https://doi. org/10.1016/j.obhdp.2005.07.002.

23. Wojciszke B, Parzuchowski M, Bocian K. Moral judgments and impressions. Curr Opin Psychol. 2015;6:50-4, https:// doi.org/10.1016/j.copsyc.2015.03.028.
24. Haidt J. Why concepts creep to the left. Psychol Inq 2016;27(1):40-5, https://doi.org/10.1080/1047840X.2016. 1115713.

25. Bee H. Child and adolescent development. Boston: Pearson Custom Publishing; 2000.

26. Labouvie-Vief G. Integrating emotions and cognition throughout the lifespan. Basel: Springer; 2015.

27. Levine K. Voter decision making: The tensions of personal identity, personal ethics, and personal benefit. Am Behav Sci. 2005;49(1):63-77, https://doi.org/10.1177/00 02764205279427.

28. Bloom PB. The public's compass: Moral conviction and political attitudes. Am Polit Res. 2013;41(6):937-64, https:// doi.org/10.1177/1532673X13481842.

29. Everett JAC, Pizarro DA, Crockett MJ. Inference of trustworthiness from intuitive moral judgments. J Exp Psychol Gen. 2016;145(6):772-87, https://doi.org/10.1037/ xge0000165.

30. Surbey MK. Adaptive significance of low levels of self-deception and cooperation in depression. Evol Hum Behav. 2011;32(1):29-40, https://doi.org/10.1016/j.evolhumbehav.2010.08.009.

This work is available in Open Access model and licensed under a Creative Commons Attribution-NonCommercial 3.0 Poland License - http://creativecommons.org/licenses/by-nc/3.0/pl/deed.en. 